\title{
PEMETAAN DAN ANALISIS KOMPETENSI INTI PADA VALUE CHAIN KRE ALANG SEBAGAI PRODUK KHAS SUMBAWA
}

\author{
${ }^{1}$ Nurul Hudaningsih, ${ }^{2}$ Eki Ruskartina \\ Program Studi Teknik Industri Fakultas Teknik \\ Universitas Teknologi Sumbawa \\ *Corresponding Author email: nurul.hudaningsih@uts.ac.id
}

Diterima
bulan September
2019

Abstrak

Kre Alang merupakan kain khas Sumbawa yang menjadi identitas bagi masyarakat Sumbawa, Nusa Tenggara Barat. Perkembangan saat ini, Kre Alang tidak hanya dimiliki oleh penduduk Sumbawa. Pada saat ini, produksi 1 lembar Kre Alang memerlukan waktu di atas 1 bulan. Sedangkan harga jual satu lembar Kre Alang di atas 1,5 juta rupiah. Waktu pengerjaan dan harga jual yang cukup tinggi ini menjadi tantangan bagi UKM Kre Alang untuk memenuhi permintaan yang tinggi. Daya saing produk didapatkan melalui pengupayaan strategi yang tepat. Untuk mengoptimalkan potensi yang dimiliki UKM Kre Alang perlu dilakukan suatu perumusan strategi pengembangan yang dapat mengeliminir berbagai kendala yang dihadapi. Pendekatan strategi yang

Diterbitkan akan dipakai adalah analisis value chain, dimana dalam analisis value chain dapat digunakan sebagai alat analisis stratejik yang digunakan untuk memahami secara lebih

bulan Oktober 2019 baik terhadap keunggulan kompetitif, dimana perusahaan dapat meningkatkan nilai tambah (value added) maupun penurunan biaya sehingga dapat membuat usaha lebih kompetitif. Analisis value chain dilakukan dengan 4 tahapan utama yaitu pengumpulan data primer dan sekunder berhubungan dengan pelaku setiap rantai nilai, aktivitas yang

Keyword : dilakukan oleh pelaku pada setiap rantai nilai nilai tambah dan nilai akhir setiap rantai

Kre Alang, Value nilai. Berdasarkan penelitian yang telah dilakukan didapatkan hasil berupa mapping value chain terdiri pelaku utama adalah supplier, pengrajin Kre alang, wholeseller dan retailer. Berdasarkan analisis value chain, kompetensi inti yang dapat menjadi dasar bagi keunggulan bersaing pengrajin Kre alang di Sumbawa adalah kemampuan para pengrajin dalam proses tenun yang tidak mudah untuk ditiru oleh penenun lain.

\section{PENDAHULUAN}

Globalisasi dan perdagangan bebas saat ini merupakan sebuah tantangan sekaligus peluang bagi UKM di Indonesia. Peluang yang muncul adalah semakin meluasnya jaringan supply dan demand. Sedangakan menjadi sebuah tantangan bagi UKM adalah persaingan bisnis yang semakin ketat. Hal ini juga dialami oleh UKM kain-kain khas daerah di Indonesia. Beberapa jenis kain dari luar Indonesia seperti batik Malaysia, Thailand, China dan Polandia ikut membanjiri pasarnasional. Persaingan dalam industri ini, mengharuskan UKM kain khas daerah di Indonesia untuk memiliki keunggulan bersaing yang berkelanjutan agar dapat bertahan dan memenangkan persaingan. Daya saing produk didapatkan melalui pengupayaan strategi yang tepat. Strategi yang akan digunakan dapat memilih diantara pilihan strategi low cost atau Diferensiasi (Porter, 1985). Selanjutnya Porter (1985) menjelaskan, Analisis value-chain merupakan alat analisis stratejik yang digunakan untuk memahami secara lebih baik terhadap keunggulan kompetitif, untuk mengidentifikasi dimana value pelanggan dapat ditingkatkan atau penurunan biaya, dan untuk memahami secara lebih baik hubungan perusahaan dengan pemasok/supplier, pelanggan, dan perusahaan lain dalamindustri.

Kre alang merupakan kain khas Sumbawa yang menjadi identitas bagi masyarakat Sumbawa, Nusa Tenggara Barat. Seperti kain-kain khas daerah di Indonesia lainnya, Kre alang digunakan oleh masyarakat Sumbawa sebagai baju adat maupun pada acara-acara adat seperti pada prosesi pernikahan. Perkembangan saat ini, Kre alang tidak hanya dimiliki oleh penduduk Sumbawa namun juga digunakan sebagai cinderamata bagi turis domestik maupun internasional yang berkunjung ke Sumbawa.

Industri Kre alang Sumbawa berpusat di Desa Poto, Kabupaten Sumbawa. Industri Kre alang merupakan salah satu industri rumahan di Sumbawa yang tetap bertahan dengan segala hambatan. Proses produksi Kre alang dilakukan secara tradisional dengan menggunakan mesin tenun tradisional dan lidi sebagai alat pembatas antar kain. Produksi 1 lembar Kre alang memerlukanwaktudiatas1bulan.Sedangkanhargaju alsatulembarKre alangdiatas1,5jutarupiah. Waktu pengerjaan dan harga jual yang cukup tinggi ini 
menjadi tantangan bagi UKM Kre alang untuk memenuhi permintaan yang tinggi.

Dari permasalahan tersebut maka akan dilakukan suatu pendekatan strategi yang bertujuan untuk mengoptimalkan potensi yang dimiliki UKM Kre alang dengan mengeliminir berbagai kendala yang dihadapi. Pendekatan strategi yang akan dipakai adalah analisis value chain, dimana dalam analisis value chain dapat digunakan sebagai alat analisis stratejik yang digunakan untuk memahami secara lebih baik terhadap keunggulan kompetitif, dimana perusahaan dapat meningkatkan nilai tambah (value added) maupun penurunan biaya sehingga dapat membuat usaha lebih kompetitif. Hal ini akan membantu para pelaku usaha baik dari hulu hingga hilir untuk memiliki daya saing terhadap kompetitor. Sehingga Kre alang dapat menjadi produk yang unggul. Sedangkan Urgensi Penelitian ini adalah belum banyak digalinya strategi pengembangan yang sistematis pada Kre alang yang merupakan sebuah aset budaya Sumbawa. Sehingga diperlukan sebuah upaya analisis yang dalam dan menyeluruh untuk pengembangan Kre alang. Penelitian mengambil Skema Penelitian Dosen Muda dikarenakan penelitian ini merupakan penelitian awal dari upaya peningkatan nilai Kre alang sebagai salah satu komoditi etnis Sumbawa. Penelitian ini diharapkan dapat menentukan peta penelitian selanjutnya tentang hal- hal yang perlu dikembangkan pada komoditi Kre alang.

\section{LANDASAN TEORI}

Analisis Value chain atau rantai nilai sudah banyak diaplikasikan untuk mengevaluasi kegiatan produksi produk-produk lokal guna meningkatkan daya saing dengan produk berskala nasional maupun international. Porter's Value chain analysis merupakan suatu analisis strategik untuk meninjau ulang segala aktivitas dalam perusahaan yang memberikan nilai tambah pada produk, dalam rangka meningkatkan keuntungan kompetitif (competititve advantage) ataupun penurunan biaya (Porter, 1985). Tujuan dari analisis value chain adalah mengevaluasi kegiatankegiatan dalam perusahaan dimana perusahaan dapat menambahkan value untuk pelanggan atau menurunkan biaya.

Melakukan pengembangan strategi bisnis pada sebuah usaha kecil dan menengah (UMKM) diperlukan sebuah upaya khusus. Menurut Ahmedova (2018) terdapat enam faktor yang dapat berpengaruh pada peningkatan daya saing UMKM yaitu akses pada keuangan, aktivitas inovasi, hak milik intelektual, internasionalisasi, Penggunaan $I C T$-sumber daya manusia-manajemen strategi, kebijakan ekonomi. Dimana value chain merupakan metode yang dapat digunakan untuk menguatkan manajemen strategi. Nariyono (2018) melakukan penelitian tentang kontribusi rantai nilai pada daya saing perikanan tuna di Kabupaten Cilacap. Penelitian ini menggunakan metode wawancara untuk pencarian data. Selanjutnya data yang diperoleh akan diolah menggunakan metode SEM (Structural Equation Modelling) untuk mendapatkan nilai kontribusi masing-masing aspek terhadap daya saing perikanan tuna. Pada penelitian tersebut didapatkan hasil bahwa daya saing perikanan tuna dapat dilakuan dengan upaya meningkatkan rantai nilai terutama pada bagian aspek operasional, outbound logistic dan service. Utomo (2017) menggunakan analisis value chain untuk penentuan kebijakan dan program pengembangan Madu Hutan Sumbawa. Pada penelitian ini, value chain digunakan untuk mengurai seluruh aktivitas yang terkait dengan produksi Madu Hutan Sumbawa. Melalui penelitian ini, penulis memberikan kesimpulan bahwa pada pengembangan Madu Hutan Sumbawa diperlukan kelembagaan berupa kelompo tani yang berperan dalam meminimalkan ketidakpastian kepemilikan sumber daya, mendukung transformasi dari pendekatan bisnis tradisional ke pendekatan yang lebih modern dan mampu mengelola seluruh bisnis secara independen, konsisten dengan nilai-nilai sosial budaya. Kelompok tani yang solid dapat meningkatkan organisasi pasar dan memulai standardisasiproduk.

Novandari (2013) melakukan penelitian tentang analisis rantai nilai pada industri Batik di Kabupaten Purbalingga. Dalam penelitian ini dilakukan pemetaan pelaku yang terlibat dalam rantai nilai dan mencari kompetensi yang diperlukan dalam rantai nilai Batik Kabupaten Purbalingga. Suhartini dan Yuliawati (2014) menganalisis peningkatan daya saing produk batik dengan analsis value chain dengan objek penelitian di daerah Sidoarjo. Selanjutnya Mangifera (2015) juga menganalisa rantai nilai pada produk industri batik tulis di Surakarta. Banyak penelitianpenelitian serupa yang dilakukan guna meningkatkan daya saing produk-produk lokal, salah satunya industri tekstil di Indonesia.

Kre-Alang merupakan kain songket khas Sumbawa. Dalam Danni (2013) disampaikan bahwa macam-macam motif pada kain (kre) yang berada di Sumbawa yaitu motif selimpat, lonto engal, kemang setange, pohon hayat, lasuji, pusuk rebong, geometris gelampok, cepa, ayam jantan, manusia Bangka dan wapak. Menurut Dinullah Rayes dalam Danni (2013), kain tenun Sumbawa bukanlah sekadar membuat motif dan ornamen, tetapi memiliki filosofi yang punya hubungan yang tidak dapat dipisahkan dengan pola kehidupan agraris warganya, kondisi alam dan lingkungan, representasi bentuk-bentuk kekerabatan dan kebersamaan dalam kehidupan komunal mereka.

Pada perkembangan penelitian, masih terbatas yang melakukan penelitian tentang upaya penyusunan stratejik Kre-Alang sebagai salah satu 
komoditi khas Sumbawa.Penelitian dan kajian tentang Kre-Alang masih terbatas pada kajian yang berhubungan dengan adat dan budaya.Sebagai ciri khas Sumbawa, Kre-Alang memiliki sebuah kelebihan untuk dikembangkan termasuk dalam komoditi industri.Oleh karena itu, dirasa perlu dilakukan penelitian mengenai analisis stratejik tentang produksi Kre-Alang dengan menggunakan analisis Value chain.

\section{MATODE PENELITIAN}

Adapun tahap-tahap dalam penelitian ini adalah sebagai berikut.

1. Tahapan pengumpulan data yang berhubungan dengan pelaku setiap rantai nilai, aktivitas yang dilakukan oleh pelaku pada setiap rantai nilai nilai tambah dan nilai akhir setiap rantai nilai. Data yang dikumpulkan terdiri dari data primer maupun data sekunder. Data primer dilakukan melalui wawancara pada stakeholder yang berhubungan dengan segala upaya pengembangan kain Kre-Alang. Stakeholder yang dimaksud antara lain pengrajin dan pengusaha Kre-Alang, pemerhati Kre-Alang yang diwakili oleh anggota LATS (Lembaga Adat Tana Samawa) serta Dinas Koperasi, Perindustrian dan Perdagangan Kabupaten Sumbawa Besar. Sedangkan data sekunder dilakukan melalui studi literatur pada instansi terkait untuk mendapatkan data pelengkap berupa strategi pengembangan Kre-Alang.

Populasi dalam penelitian adalah semua pelaku yang terkait dengan usaha komoditas kain Kre-Alang yang terdapat di Kabupaten Sumbawa Besar-Nusa Tenggara Barat. Sedang sampel ditentukan secara non probabilistik dengan entry point adalah pengrajin kemudian dilakukan penelusuran dengan sistem bola salju untuk mendapatkan sampel pada titik berikutnya hingga sampai ke konsumen, hal ini dilakukan untuk merunut alur aliran produk yang dimulai dari hulu ke hilir.

2. Tahap Mapping Value chain

Setelah teridentifikasi pelaku utama rantai nilai dan pelaku-pelaku lain yang diperoleh dengan merunut ke belakang (go backward) maupun ke depan (go forward) maka ditentukan pendapatan (gain) setiap pelaku yang diperoleh melalui hubungan input- output.

3. Tahap Analisis Value chain

Langkah dalam menganalisis dengan menggunakan analisis value chain:

a. Mengidentifikasi aktivitas value chain. Memisahkan kegiatan atau operasi pada usaha pengrajin Kre-Alang menjadi beberapa aktivitas bisnis, dengan cara mengelompokkan aktivitas atas proses tersebut ke dalam kategori primer atau pendukung.

b. Melakukan pendataan dan analisis kompetensi inti pada value chainKre alang Sumbawa.

\section{HASIL DAN PEMBAHASAN}

Gambaran Umum Industri Kre alang-Sumbawa Berdasarkan informasi dari Diskoperindag Sumbawa, pengrajin Kre alang-Sumbawa menyebar di beberapa lokasi antara lain di Desa Poto , Desa Boak dan Desa Mapin Rea. Namun Pengrajin Kre alang di Sumbawa terpusat pada Dusun Samri, Desa Poto, Kecamatan Moyo Utara.Berdasarkan data yang didapatkan dari hasil wawancara dengan Ka.Sie Industri DISKOPERINDAG Kabupaten Sumbawa tercatat 67 pengrajin.Hanya saja saat ini tidak semua aktif dan melakukan produksi Kre alang dengan rutin.Pada Dusun Samri terdapat kelompok usaha Kre alang yang saat ini masih aktif dan terus berkembang.Nama Kelompok Usaha tersebut adalah Kemang Langit.Saat ini Kemang Langit diketuai oleh bu Jaidah. Kelompok usaha ini didirikan dengan tujuan untuk memberikan kordinasi kepada pada pengrajin Dusun Samri apabila terdapat bantuan dari pemerintah maupun lembaga lain. Bantuan yang pernah didapatkan oleh kelompok usaha ini antara lain pelatihan tentang bisnis era 4.0 oleh Diskominfotik Kab.Sumbawa dan pelatihan produksi kain tenun oleh Diskoperindag Kab.Sumbawa.

Pengerjaan Kre alang masih menggunakan alat tradisional yang diproduksi oleh penduduk sekitar sentra. Kendala umum yang dihadapi oleh para Pengrajin Kre alang adalah kendala pemasaran. Hal ini diperparah dengan semakin banyaknya kain Kre alang yang diproduksi oleh pengrajin daerah lain yang memiliki harga lebih murah.

\section{Mapping Value Chain}

Mapping value chain pada gambar diatas menggambarkan distribusi Kre alang dari produksi hingga konsumen akhir melewati tahapan dan proses yang berbeda. Mapping value chain terdiri dari tiga bagian yaitu aktivitas dalam value chain, pelaku utama value chain, dan lembaga- lembaga terkait yang menunjang keberlangsungan value chainKre alang. Adapun penjelasan masing-masing poin adalah sebeagai berikut

a. Aktivitas Utama Value chain

1. Logistik ke Dalam (Inbound logistic)meliputi aktivitas penerimaan, penyimpanan, pengelolaan dan pengontrolan persediaan bahan baku, pengangkutan dan pengembalian material kepada pemasok. Bahan baku pembuatan Kre alang secara umum adalah benang warna, benang emas. Bagi pengrajin yang memiliki skala kecil maka bahan baku didapatkan dari toko yang terdapat di Sumbawa. Namun bagi pengrajin yang 
memiliki skala menengah dan besar, bahan baku didapatkan dari toko bahan di Mataram hingga mendatangkan bahan dari Lampung.

Bahan baku yang digunakan oleh pengrajin Kre alang Sumbawa memiliki beberapa variasi. Ada 3 jenis bahan baku yang digunakan. Perbedaan bahan baku tersebut berpengaruh kepadakualitas hasil kain. 1) Bahan baku benang sintesis 2)Bahan baku kain semi sintesis 3) Bahan baku serat alam. Bahan baku jenis pertama dapat diperoleh dari toko bahan di Sumbawa. Sedangkan untuk tipe bahan kedua daidapatkan di toko bahan di Kota Mataram dan jenis bahan ketiga harus didatangkan dari Lampung. Karena persediaan yang tidak selalu ada, jarak yang jauh serta harga yang mahal maka bahan baku jenis ketiga jarang digunakan oleh para pengrajin, kecuali apabila ada permintaan khusus. Pengadaan bahan baku ini dlakukan langsung oleh setiap pengrajin ke masingmasing toko. Adakala pengadaan dilakukan secara kolektif antar pengrajin mengingat jarak sentra ke lokasi toko di kota cukup jauh.

Penyimpanan bahan baku dilakukan dengan cara yang sederhana. Setiap benang disimpan disebuah tempat penyimpanan khusus dan diletakkan di tempat yang bersih dan kering. Benang disimpan berdasarkan warna ditujukan agar memudahkan proses pemilihan bahan tidak kusut dan rumit. Penyimpanan bahan baku dapat berlangsung sampai 5 tahun. Hal ini dikarenakan bahan baku yang digunakan merupakan benang sintesis yang dapat bertahan lama.

Sejauh ini belum terdapat pengelolaan dan pengontrolan bahan baku. Belum terdapat kerjasama antara pengrajin dengan sumber bahan baku baik yang terdapat di Sumbawa maupun yang terdapat di luar kota (Mataram dan Lampung). Sehingga kontinyuitas dan kualitas persediaan bahan baku tidak dapat dijamin. Sebelum melakukan produksi, pengrajin melakukan pengecekan bahan baku yang tersedia di rumah mereka. Apabila dirasa kurang maka pengrajin segera ke toko untuk melakukan pembelian. Kekurangan yang terjadi adalah apabila di toko barang tidak tersedia maka proses produksi secara otomatis akan terhambat dan tidak dapat dimulai.

\section{Operasi (Operation)}

Kre alang merupakan kain khas Sumbawa yang dibuat dengan cara menenun secara tradisional. Proses pembuatannya memerlukan ketelitian dan keahlian yang tinggi serta waktu pembuatan yang relatif lama. Tidak heran jika kain khas Sumbawa ini memiliki nilai jual yang tinggi. Pada proses pembuatan kre alang, terdapat tiga tahapan yaitu merane, begurin dan nesek.

Merane merupakan tahapan awal pada proses pembuatan kre alang. Tahapan ini merupakan proses penataan benang pada alat yang akan digunakan sehingga membentuk dasar kre alang. Pada tahapan merane terdapat beberapa aktivitas. Aktivitas pertama yaitu membentang benang. Benang yang akan digunakan diletakkan pada alat yang tersusun dengan tingkat empat. Lalu tiap ujung benang tersebut disatukan untuk dibentangkan sesuai pola pada alat rane. Aktivitas kedua adalah merakit alat. Proses ini merupakan lanjutan dari bentang benang. Alat yang menjadi pondasi atau struktur kre alang diselipkan pada pola benang yang telah terbentuk. Aktivitas ketiga yaitu isi sisir merupakan proses penyelipan benang satu persatu ke dalam sisir khusus kre alang. Beberapa pengrajin menggunakan duri landak sebagai bantuan untuk menyelipkan benang. Setelah itu, dilanjutkan dengan gulung benang yaitu proses dimana benang yang telah disatukan dengan alat lalu dibentangkan hingga lurus agar kain yang dihasilkan nantinya dapat rapi dan padat. Aktivitas berikutnya adalah membuat tata benang yang merupakan proses memasukkan benang pada benang sebelumnya yang telah menyatu dengan alat-alat agar membentuk pembatas pada kain yang akan dibuat. Setelah pembatas dibuat, dilanjutkan dengan proses merangkai jarum selit yaitu proses penyelipan lidi sesuai dengan pola yang sudah dibuat.Ratarata pengrajin menghitung lidi untuk menghindari kesalahan dalam pengerjaan proses nyongkat dan pembuatan motif. Aktivitas terakhir pada tahapan merane adalah merakit motif yaitu proses merumuskan bentuk motif sesuai yang diinginkan berdasarkan pola. Kebanyakan pengrajin masih membuat pola dengan melihat rumus pola pada buku karena cukup rumit dan sulit untuk dihafal cepat. Namun ada sedikit pengrajin yang bisa menghafalkan rumus pola motif.

Tahapan selanjutnya yaitu tahapan begurin yang merupakan proses yang dilakukan untuk memperjelas motif dengan cara menyelipkan lidi dan mengangkat gurin satu per satu. Begurin dilakukan secara berulang-ulang hingga jumlah gurin habis. 
Tahapan terakhir yaitu nesek. Nesek merupakan proses penyatuan benang menjadi kain. Dalam proses nesek terdapat dua aktivitas yaitu nyongkat dan menenun. Nyongkat merupakan proses duplikat pembuatan kemang yang diikuti dari hasil gurin dengan menyelipkan lidisehingga membentuk motif yang ditentukan. Proses nyongkat ini dilakukan hingga jumlah lidi yang ditentukan habis. Menenun adalah proses penyatuan benang yang telah terstruktur rapi dengan pola motif hinggamenjadi kain. Proses menenun memerlukan waktu pengerjaan yang lama karena rumit dan harus teliti agar menghasilkan kre alang dengan kualitas yang bagus.

\section{Logistik ke luar (Outbound logistic)}

Aktivitas yang berkaitan dengan pengumpulan, penyimpanan dan pendistribusian produk jadi ke konsumen.Belum ada pengrajin yang memiliki outlet untuk memajang produk mereka.Saat ini ada 1 outlet bersama bagi kerajinan Kre alang-Sumbawa yang disediakan olehDiskoperindag Kabupaten Sumbawa.Tidak ada tempat penyimpanan khusus untuk produk Kre alang yang telah selesai diproduksi. Setelah produksi selesai, Kre alangakan disimpan dalam lemari kayu untuk menghindari debu dan kotor.

Upaya pemasaran yang dilakukan oleh kelompok pengrajin adalah mengikuti pameran produk yang diadakan baik dalam wilayah NTB maupun wilayah diluar NTB.

\section{Pemasaran dan Penjualan (Marketing} and Sales)

$\begin{array}{crr}\text { Aktivitas } & \begin{array}{r}\text { Pemasaran dan } \\ \text { kegiatan }\end{array} & \begin{array}{r}\text { Penjualan } \\ \text { untuk }\end{array}\end{array}$ mengenalkan/menyampaikan produk dan closingpembeli melalui iklan, promosi, pemilihan distributor dan penentuan harga. Dalam memasarkan Kre-alang, pengrajin belum menggunakan iklan.Pengrajin sebatas menggunakan media pameran atau ekspo untuk mengenalkan produk ke masyarakat Sumbawa maupun masarakat luar Sumbawa.Promosi dari para pengusaha Kre alang sebagian besar belum menggunakan iklan untuk menjual Kre alang. Proses promosi dilakukan dengan kemampuan getok tular atau promosi dari mulut ke mulut. Namun ada sebagian kecil retailer Kre alang yang mempromosikan produk mereka menggunakan media massa online. Media online yang lazim digunakan adalah Facebook dan Instagram.

Penjualan Kre alang dapat melalui 2 pintu, yaitu di wholesaler dan retailer.Wholesaler menjual Kre-Alang dengan jumlah besar sedangkan retailer menjual Kre alang dengan jumlah kecil.Harga Kre-Alang yang sampai ke customer dengan spesifikasi bahan berupa benang nilon melalui wholesaler dalam kisaran harga Rp 1.200.000 - Rp 1.300.000 per lembar Kre alang dan selendang.Harga ini akan meningkat apabila pembelian dilakukan di retailer. Kisaran harga jual Kre alang dari retailer adalah $\mathrm{Rp} 1.300 .000-\mathrm{Rp}$ 1.500 .000 per lembar Kre alang dan selendang dengan spesifikasi ang sama. Harga ini lebih tinggi apabila dibandingkan dengan harga kain tenun dari Pengrajin Tenun di darah Bima dan Lombok.

Dalam penentuan harga jual, pengrajin pada umunya menggunakan metode taksiran kemampuan beli masyarakat Sumbawa, sebagai customer, serta biaya bahan baku. Pengrajin belum melakukan perhitungan biaya tenaga kerja, biaya overhead produksi, biaya pengiriman dan margin keuntungan.

\section{Pelayanan (Service)}

Aktivitas Pelayanan yang dimaksudkan adalah pelayan setelah penjualan (purna jual).Aktivitas ini terdiri dari penyediaan jasa untuk mempertahankan nilai produk setelah purna jual. Sepanjang value chain Kre-Alang baik pada pengrajin, wholesaler dan retailer belum melakukan pelayanan purna jual. Belum terdapat usaha untuk melakukan perbaikan apabilaterdapat produk yang berada di bawah standar.

\section{b. Segmen Utama Value chain}

Segmen utama value chainKre alang Sumbawa terdiri dari segmen Upstream, Midstream dan Downstream.Penjabaran masingmasing segmen adalah sebagai berikut

Segmen Upstream, terdiri dari supplier bahan baku utama dan bahan baku penunjang. Bahan baku utama Kre alang adalah benang, sedangkan bahan baku penunjang adalah benang emas. Selain itu juga terdapat produsen alat tenun yang menjadi bagian dari segmen ini.

Segmen Midstream, terdiri dari produsen Kre alang. Pada segmen ini terdapat proses penambahan nilai terbesar sepanjang rantai value chainKre alang. Pada segmen ini terjadi proses transformasi material yang semula merupakan benang menjadi benang-benang yang disusun mengikuti pola tertentu.

Segmen Downstream, terdiri dari proses distrusi ke konsumen akhir. Pada segmen ini proses pengiriman Kre alang menjadi inti.

c. Pelaku Utama Value chain

Pelaku Utama Value chainKre alang - 
Sumbawa adalah :

- Supplier

- Pengrajin

- Pengepul

- Pengecer

d. Lembaga-lembaga Penunjang Keberlangsungan Value chain

Dinas Koperasi, Perindustrian dan Perdagangan Kabupaten Sumbawa selama ini telah melakukan pembinaan terhadap pengembangan produksi Kre alang. Pembinaan tersebut berupa pelatihan dan penyaluran bantuan alat kepada para pengrajin. Adapun pelatihan yang telah difasilitasi oleh Dinas Koperasi, Perindustrian dan Perdagangan
Kabupaten Sumbawa adalah sebagia berikut :

- Pelatihan peningkatan sumber daya manusia berupa pelatihan wirausaha dan pelatihan tenun

- Pelatihan penggunaan alat tenun mesin

Sedangkan bantuan diluar pelatihan adalah sebagai berikut :

- Bantuan permodalan berupa penyaluran mesin tenun mesin dan beruga (tempat produksi)

- Bantuan pemasaran berupa pameran dan ekspo

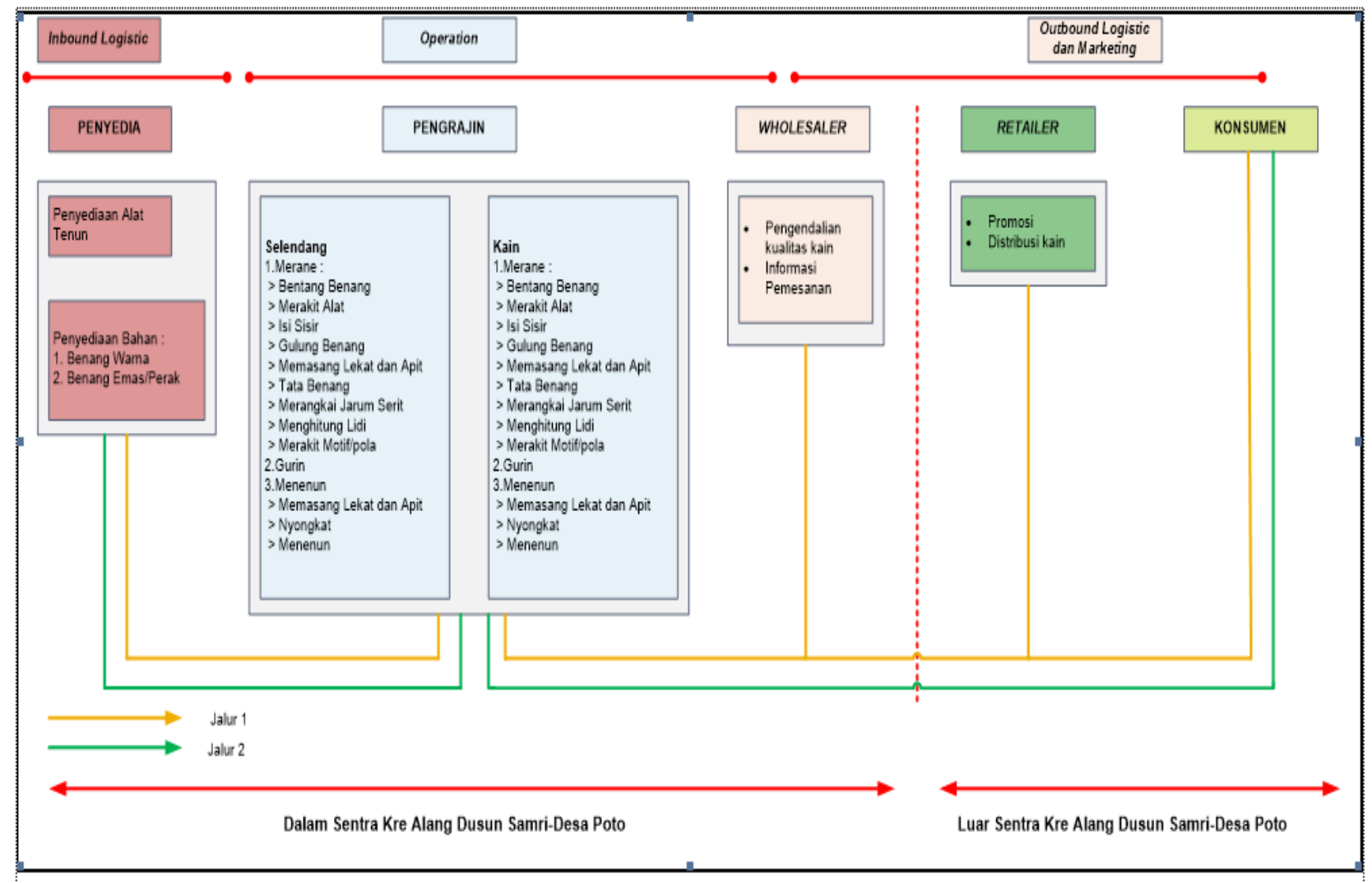

Gambar 1. Mapping Value Chain Kre Alang-Sumbawa 


\section{PENUTUP}

\section{Kesimpulan}

Berdasarkan penelitian yang telah dilakukan didapatkan kesimpulan sebagai berikut :

1. Dalam mapping value chain terdiri dari tiga segmen utama yang meliputi segmen upstream, segmen midstream dan segmen downstream. Sedangkan pelaku utama dalam value chainKre alang adalah supplier, pengrajin Kre alang, wholeseller dan retailer.

2. Berdasarkan analisis value chain, kompetensi inti yang dapat menjadi dasar bagi keunggulan bersaing pengrajin Kre alang di Sumbawa adalah kemampuan para pengrajin dalam proses tenun yang tidak mudah untuk ditiru oleh penenun lain.

\section{REFERENSI}

Ahmedova, Sibel. 2015. Factors for Increasing the Competitiveness of Small and Medium-Sized Enterprises (SMEs) In Bulgaria. Procedia Social and Behavioral Sciences 195 (2015) $1104-1112$.

Danni, Gufron. 2013. Nilai Simbolis Seni Kelingking Kain Songket Sumbawa. Skripsi Program Studi Pendidikan Seni Rupa, Universitas Negeri Yogyakarta, Yogyakarta.
Mangifera, Liana. 2015. Analisis Rantai Nilai ( Value chain ) Pada Produk Batik Tulis Di Surakarta. Jurnal Manajemen dan Bisnis BENEFIT, Vol. 19, No. 1,24-3.

Nariyono, Bambang, dkk. 2018. Kontribusi Rantai Nilai terhadap Peningkatan Daya Saing Perikanan Tuna di Kabupaten Cilacap dan Sekitarnya. Jurnal Kebijakan Perikanan Indonesia, Vol.10, No.1,11-23.

Novandari, Weni. 2013. Pemetaan Dan Analisis Kompetensi Inti UKM Batik Di Kabupaten Purbalingga Dengan Pendekatan Value chain. Jurnal Ekonomi dan Bisnis, Vol.12, No.01.

Porter, M.E. 1985. Competitive Advantage: Creating And Sustaining Superior Performance. New York. Free Press.

Suhartini, Yuliawati, Evi. 2014. Analisis Value chain Untuk Peningkatan Daya Saing Produk Batik. Prosiding Seminar Nasional MMT XXI - ITSSurabaya.

Utomo, Marcellinus. 2018. Analysis Of Wild Honey Development Policy For Local People Livelihoods Improvement In The Sumbawa District. Jurnal PenelitianKehutanan Wallacea, Vol. 7, No.1, 13 -23. 